\title{
ANALYSIS OF THE SPECIFIC PROFILE OF ART ORGANIZATIONS IN PLOVDIV, BULGARIA

\author{
Margarita Ruseva $^{1}$, Vesela Kazashka ${ }^{2}$, Vasil Kolev ${ }^{3}$
}

\begin{abstract}
This paper presents the results of fundamental research into the cultural organizations of Plovdiv, Bulgaria. The overarching aim of the research is to determine the specific profile of art organizations. Factors examined are areas of work, types of ownership, and category (small, medium, or large enterprises). An objective is to collect and analyze data for several projects that are developed and funded by the art organizations over a five-year period. Empirical research and analysis of quantitative and comparative data are conducted to achieve these objectives. This involves a survey using a questionnaire developed by experts with two main groups of questions. The first group is a set of general questions targeting the specific profile of the organizations, and the second aims to specify the type, area, frequency, and source of funding for the projects developed by the art organizations. The obtained data and results provide the profile and the financial framework of the cultural and art organizations in Plovdiv city, Bulgaria and can be used as a basis for further studies and research.
\end{abstract}

UDC Classification: 7.1/06; DOI: http://dx.doi.org/10.12955/cbup.v6.1239

Keywords: Art organizations, Mapping, Plovdiv

\section{Introduction}

The foundations of society and people's lives eAxist in a region's cultural heritage and its cultural and creative infrastructure. This includes buildings in cities, natural sights, and archaeological finds. Artistic infrastructure is a prerequisite and a necessity for developing cultural and creative potential of people.

Interest in cultural organizations of Plovdiv arises because the cultural industries in the city represent about $10 \%$ of the economy. At the same time, the topic is justified by the fact that over 7 million people in Europe work in the field of cultural organizations. ${ }^{4}$

Plovdiv is onAAe of the oldest cities in Europe and is the cultural capital of Bulgaria. In a way, these facts make the city an open stage for the arts. This status is a prerequisite for cultural organizations to be able to work in the area of performing arts as confirmed by the data from National Statistical Institute (NSI), which revealed most art organizations fall within that category. The performing arts require time, place, action, and public. The performers can be actors, comedians, dancers, magicians, or singers, using makeup, wigs, and special costumes. Hence, the performing arts are diverse and widespread, suiting the broader audience. The main task of such cultural organizations is to perform creative and cultural products and to disseminate and preserve cultural values.

This study focuses on the cultural and creative organizations of the city of Plovdiv with the aim to outline their specific profile. The objective is to collect and analyze data for a number of developed and funded projects of the art organizations over five years. The project funding is a tool for the development of the cultural organizations.

The proposed topic is relevant because the Bulgarian scientific and economic situation lacks an indepth analysis of this organizational type and particularly in applying the 'market' principle.

\section{Data and Methodology}

The research toolkit was developed using conceptual apparatus and indicators, comprehensively structured in a questionnaire. The grouping of the questions was bi-directional. The first group focused entirely on profiling the cultural organizations. The task was to establish the location of the organizations, their form of ownership, the size of the enterprise, and the area of culture and arts in which they operated. Also included were questions regarding the sustainability and development of the organizations in the free-market environment. The aim of the second group of questions was to obtain data for analysis of the type, frequency, and implementation of projects by the cultural organizations.

\footnotetext{
${ }^{1}$ Plovdiv University, ruseva_margarita@mail.bg

2 Academy of Music, Dance and Fine Arts -Plovdiv, vesela.kazashka@gmail.com

${ }^{3}$ Academy of Music, Dance and Fine Arts -Plovdiv, vasko_kolev@abv.bg

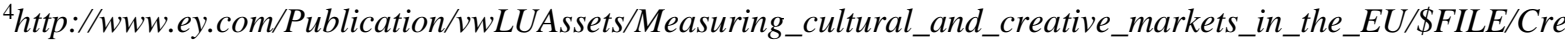
ating-Growth.pdf
} 
To achieve the specific objective of the research, additional questions were included to determine how many project proposals were developed by cultural organizations over the past five years, how many are the successful projects in the last five years and which funding sources were used. Also, the study assessed the funding sources, local or foreign, that the cultural organizations were concentrating their efforts on developing and implementing projects.

Data were obtained from the NSI. The total number of companies registered in 2016 was 272 . The cultural organizations registered and operating under different legal frames involved two large registered groups: profit organizations operating under the Bulgarian Trade law and non-profit organizations operating under the Law for Nonprofit Organizations.

They were differentiated by economic activity as presented in Kazashka et al., 2017. The distribution of the organizations by their economic activity was 121 for publishing activity, 57 for performing arts, 55 for photography, 13 for creative activities in literature and art, 7 in radio and TV programs, 6 in libraries and archives, 5 in music records and producing, 4 in museums, 3 in preservation and maintaining of cultural and historical heritage, and 1 in manufacturing of musical instruments. Organizations performing publishing activities were not included in the analysis as they will be considered in a separate study.

To determine an organization as micro, small, or medium-sized enterprise, Articles 3 and 4 of the Bulgarian Law for Small and Medium-Sized Enterprises were used, issuing the following criteria: Medium-sized enterprises have less than 250 personnel with an annual turnover under BGN 97500 000 (EUR 49850958 EUR) or a total capitalization of under BGN 84000000 (EUR 42000 000), or both. Small-sized enterprises have personnel of less than 50 with an annual turnover under BGN 19 500000 (EUR 9750 000) or their total capitalization is under BGN 19500000 (EUR 9750 000), or both. Micro-sized enterprises have less than 10 personnel and an annual turnover under BGN 3 900000 (EUR 1800 000) or a total capitalization of under BGN 3900000 (EUR 1800 000), or both.

Data were analyzed using MS Excel 2018 and software for social research, namely, IBM SPSS, version 24.0. Data analysis involved decomposing the researched subject into component elements, summarizing the characteristics and synthesizing conclusions with study results reported according to a level of significance $(\alpha=0.05)$ and probability (95\%).

The specific profile of the cultural organizations in Plovdiv, Bulgaria is presented in Tables 1-5.

\section{Results and Discussion}

To the question: "To which area of work belongs your cultural organization?", $71.8 \%$ of the managers answered the performing arts (opera, theater, music, dance); 15,4\% with organizations are working in the area of the contemporary visual arts; $7.7 \%$ with cultural organizations working in the area of preserving cultural-historical heritage; and $5.1 \%$ with cultural organizations connecting art, culture, education and new technologies, intercultural dialog, partnerships, mobility, and European cultural cooperation (Table 1).

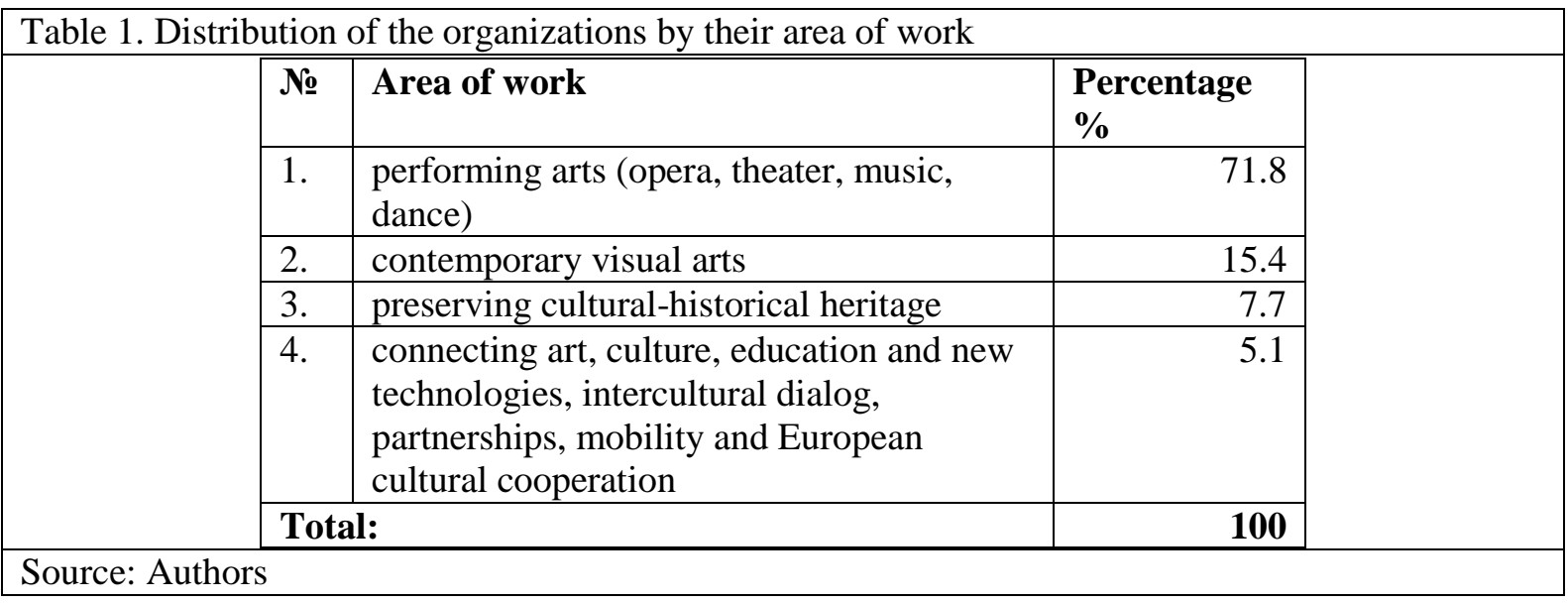

The cultural organizations were differentiated according to their type of ownership as $56.4 \%$ government and 43.6 private (Table 2 ). 


\begin{tabular}{|c|c|c|c|}
\hline & № & Ownership & Percentage \% \\
\hline & 1. & Government & 56.4 \\
\hline & 2. & Private & 43.6 \\
\hline & \multicolumn{2}{|c|}{ Total: } & 100 \\
\hline
\end{tabular}

Results show that the cultural organizations involved $69.2 \%$ micro-sized enterprises (up to 50 personnel); $25.6 \%$ small-sized enterprises (50 to 200 personnel), and 5.1\% are medium-sized enterprises (250 personnel). Results are shown in Table 3.

\begin{tabular}{l}
\hline \multicolumn{2}{|l|}{ Table 3. Distribution by the size of the enterprise } \\
$\qquad$\begin{tabular}{|l|l|r|}
\hline$№$ & Category of the organization & Percentage (\%) \\
\hline 1. & Micro-sized enterprise & 69.2 \\
\hline 2. & Small-sized enterprise & 25.6 \\
\hline 3. & Medium-sized enterprise & 5.1 \\
\hline Total: & $\mathbf{1 0 0}$ \\
\hline
\end{tabular} \\
Source: Authors \\
\hline
\end{tabular}

The amount of interest in the output of cultural organization was determined according to annual turnover for the last five years (Table 4) and the number of newly employed personnel for the last year (Table 5).

\begin{tabular}{|c|c|c|c|}
\hline & № & Annual turnover & Percentage (\%) \\
\hline & 1. & Up to 25000 EUR & 42.8 \\
\hline & 2. & From 25000 to $50000 \mathrm{EUR}$ & 9.5 \\
\hline & 3. & Over 50000 EUR & 47.7 \\
\hline & To & & 100 \\
\hline
\end{tabular}

\begin{tabular}{|c|c|c|c|}
\hline \multicolumn{4}{|c|}{ Number of newly employed personnel } \\
\hline & 1. & Up to 2 people & 66.7 \\
\hline & 2. & From 2 to 10 people & 28.6 \\
\hline & 3. & Over 10 people & 4.7 \\
\hline & \multicolumn{2}{|c|}{ Total: } & 100 \\
\hline
\end{tabular}

Working in a market economy, cultural organizations experience great difficulties in securing funding for the performance of their activities. One way to ease the financial burden is to develop and implement projects funded by national and European programs. This has prompted the interest of this research to determine the extent of possibilities for financing cultural organizations using national and international funding instruments. At the national level, the main funding institution for culture is the National Culture Fund, and at the European level, the program Creative Europe of the European Commission is the main financial mechanism.

The total budget for Creative Europe for 2014-2020 is EUR 1.46 billion with the program supporting projects in the areas of art, culture, and audio vision. The National Culture Fund is a legal entity with a budget supported by the Ministry of Culture and was created in 2000. It supports the development of culture by fundraising, managing, and dispersing funds for the implementation of the National Cultural Policy. More than 110 calls for projects were announced for 2000-2017. In more than 5000 projects submitted by various organizations, about 2500 projects were funded, with a total worth of approximately BGN 4500000 (EUR 2250 000). The financial instruments for improving the activities of cultural organizations are available to both public and private organizations. 
The results for the number of project proposals submitted and that were successful are presented in Tables 6-7. Table 8 shows the preferred funding sources.

\begin{tabular}{|c|c|c|c|}
\hline & № & Number of project proposals & \multirow{2}{*}{ Percentage \% } \\
\hline & 1. & Up to 5 & \\
\hline & 2. & Over 5 up to 10 & 14.3 \\
\hline & 3. & Over 10 & 14.3 \\
\hline & \multicolumn{2}{|c|}{ Total: } & 100 \\
\hline
\end{tabular}

\begin{tabular}{|c|c|c|c|}
\hline & № & Number of successful projects & Percentage \% \\
\hline & 1. & Up to 5 & 66.7 \\
\hline & 2. & Over 5 up to 10 & 9.5 \\
\hline & 3. & Over 10 & 23.8 \\
\hline & \multicolumn{2}{|c|}{ Total: } & 100 \\
\hline
\end{tabular}

The results showed that, on average, the majority of cultural organizations develop and implement either none or one project per year, which is insufficient to have a lasting effect on their development.

\begin{tabular}{l}
\hline \multicolumn{2}{|l|}{ Table 8. Preferred funding sources for the cultural organizations } \\
\hline \\
$\qquad$\begin{tabular}{|l|l|r|}
\hline$№$ & Funding sources & Percentage \% \\
\hline 1. & Bulgarian & 26.3 \\
\hline 2. & Foreign & 73.7 \\
\hline Total: & $\mathbf{1 0 0}$ \\
\hline
\end{tabular} \\
\hline
\end{tabular}

The high percentage of cultural organizations apply for projects from foreign funding sources, which have a higher amount of funds allocated to artistic and creative activity than those locally. However, an application to foreign sources requires additional competencies, such as digital and linguistic, and abilities to work in international teams.

The largest number of developed projects from the cultural organizations are in the area of infrastructure, followed by the artistic and creative projects. The lowest share of projects is in the area of mobility and research (Table 9).

\begin{tabular}{|l|r|}
\hline \multicolumn{2}{|l|}{ Table 9. Project area } \\
\hline \\
\begin{tabular}{|l|l|r|}
\hline $\mathbf{N o}$ & Type of projects & Percentage (\%) \\
\hline 1. & Infrastructural projects & 58.5 \\
\hline 2. & Mobility projects & 3.8 \\
\hline 3. & Research projects & 35.8 \\
\hline 4. & Artistic and creative projects & $\mathbf{1 0 0}$ \\
\hline
\end{tabular} \\
\hline
\end{tabular}

The mobility programs for financing transport costs of artists, which include cultural and artistic representatives for participation in international, national, and local cultural forums or visits of foreign artists and representatives of culture and arts, are some of the most common forms of enhancing and sustaining the cultural and creative environment.

Research projects are more typically developed in art universities, research institutes, and museums, galleries. Through such research, new technologies relating to the arts are developed and implemented, analyzes are carried out, and innovative ideas are formulated and introduced. 


\section{Conclusion}

This basic research achieved its objective of collecting and processing the large amount of information on the cultural organizations of Plovdiv, Bulgaria. The main aim to define the specific profiles of the cultural organizations was achieved. Indications showed that the cultural organizations had difficulties with funding their projects. Access to funding was mainly problematic because assets and collaterals are of cultural organizations are mostly immaterial. Furthermore, they are affected by limitations of the market and an uncertainty of demand. Establishing the exact causes is a subject for further in-depth research. In conclusion, the results of this fundamental research are the basis for future research in this area and provide useful guidance for the development of local cultural policies.

\section{Acknowledgment}

The article is founded by the project DM05/2/2016 "Art management: Plovdiv - new tendencies and classical art (ART)”, Bulgarian Science Fund, Ministry of Education and Science.

\section{References}

Kazashka V., Ruseva M., Stoyanova P. (2017). Mapping and ranging of cultural and creative industries in the city of Plovdiv. CBU International Conference "Innovation in Science and Education", pp. 633- 638, Prague, 2017.

National Statistical Institute: Standard statistical indicators list for 2016 http://www.nsi.bg 